\title{
Produção de Leite de Vacas Mestiças Holandês x Zebu em Pastagem de Capim-Elefante, Manejada em Sistema Rotativo com e sem Suplementação durante a Época das Chuvas
}

\author{
Fermino Deresz ${ }^{1}$
}

\begin{abstract}
RESUMO - Os objetivos deste trabalho foram estudar os efeitos da suplementação da pastagem de capim-elefante com concentrado sobre a produção e composição do leite e variação de peso vivo de vacas mestiças Holandês x Zebu. Os tratamentos foram: sem concentrado (SC) e com $2,0 \mathrm{~kg}$ de concentrado/vaca/dia (CC). O experimento foi realizado durante a época das chuvas. A área foi dividida em 44 piquetes de $606 \mathrm{~m}^{2}, 22$ para cada tratamento, representando duas repetições de área, constituída cada uma de 11 piquetes. Foram usadas 12 vacas, seis por tratamento, tendo em média 30 dias de lactação e peso vivo médio de $488 \mathrm{~kg}$. O delineamento experimental foi em blocos ao acaso e os blocos foram formados com base na produção de leite e no peso vivo das vacas no início da lactação. A pastagem foi manejada em sistema de pastejo rotativo com três dias de ocupação/piquete e 30 dias de descanso. A taxa de lotação foi de 4,5 vacas/ha. A pastagem foi adubada durante a estação chuvosa com $200 \mathrm{~kg} / \mathrm{ha} /$ ano de $\mathrm{N}$ e de $\mathrm{K}_{2} \mathrm{O}$, parceladas em três aplicações iguais. Foram aplicados também $40 \mathrm{~kg} / \mathrm{ha} /$ ano de $\mathrm{P}_{2} \mathrm{O}_{5}$ e $1.000 \mathrm{~kg} / \mathrm{ha} /$ ano de calcário dolomítico. As produções médias de leite corrigido para $4 \%$ de gordura foram de 11,4 e 12,6 kg/vaca/dia e o ganho médio diário de 114 e $180 \mathrm{~g}$, para os tratamentos SC e CC, respectivamente. Houve diferença entre os tratamentos na produção de leite, mas não no ganho de peso.
\end{abstract}

Palavras-chave: adubação, capim-elefante, concentrado, pastejo rotativo, peso vivo, produção de leite, vacas mestiças

\section{Milk Yield of Crossbred Holstein x Zebu Cows Grazing Elephant Grass Pasture Rotationally Managed Supplemented or not with Concentrate}

\begin{abstract}
The objectives of this trial were to study the effect of supplementation with concentrate on elephant grass pasture rotationally managed on milk yield and composition and live weight changes of crossbred Holstein x Zebu cows. The treatments were: no concentrate (NC) and $2 \mathrm{~kg}$ concentrate/cow/day (WC). The experiment was carried out during the rainy season. The area was divided in 44 paddocks of $606 \mathrm{~m}^{2}$ each, with 22 for each treatment, with two areas replication of 11 paddocks each. Twelve crossbred cows were utilized (six cows/treatment), with 30 days of lactation and $488 \mathrm{~kg}$ of live weight on average. The cows were allocated to the treatments according to a completely randomized block design. The blocks were based on milk yield and body weight of cows at the beginning of lactation. The pasture was managed in a rotational system with 30 days grazing interval and three days of grazing in each paddock. The stocking rate was established at $4.5 \mathrm{cows} / \mathrm{ha}$. The pasture was fertilized with $200 \mathrm{~kg} / \mathrm{ha} / \mathrm{yr}$ of $\mathrm{N}_{\text {and }} \mathrm{K}_{2} \mathrm{O}$, divided in three equal applications. It was also applied $40 \mathrm{~kg} / \mathrm{ha} / \mathrm{yr}$ of $\mathrm{P}_{2} \mathrm{O}_{5}$ and $1,000 \mathrm{~kg} / \mathrm{ha} / \mathrm{yr}$ of dolomite limestone. The average fat corrected (4\%) milk yield was 11.4 and $12.6 \mathrm{~kg} / \mathrm{cow} /$ day and the average daily gain during the experimental period was 114 and $180 \mathrm{~g}$ per cow for treatments $\mathrm{NC}$ and WC, respectively. There was a significant treatment effect for milk yield, but no effect on live weight gain.
\end{abstract}

Key Words: concentrate, crossbred cows, elephantgrass, fertilization, milk yield, rotational grazing, live weight

\section{Introdução}

O capim-elefante (Pennisetum purpureum, Schum.) é uma gramínea perene, de alto potencial de produção de forragem, adaptada às condições climáticas predominantes em quase todo o País. Entretanto, em muitas regiões, aproximadamente, 70 a $80 \%$ da sua produção concentra-se na época das chuvas. Esta estacionalidade de produção de forragem é atribuída às baixas precipitações, pouca luminosidade e baixas temperaturas que ocorrem no período de inverno.
Atualmente, nota-se tendência para produção de leite a pasto, objetivando à diminuição dos custos de produção, devido principalmente ao elevado preço do concentrado. Ultimamente, existe grande demanda por informações sobre o uso do capim-elefante e outras gramíneas tropicais manejadas em sistema de pastejo rotativo para produção de leite e carne, visando, principalmente, à diminuição dos custos de produção. A margem de lucro por litro de leite vendido é muito pequena na maioria das fazendas, especialmente sob condições de confinamento, devido ao elevado preço do concentrado. Na Nova Zelândia, HOLMES (1995) 
afirma que a produção de leite a pasto é o sistema mais econômico.

O capim-elefante é a gramínea tropical que apresenta o maior potencial de produção de matéria seca (FARIA, 1994), desde que as condições edafoclimáticas e de manejo sejam favoráveis. Durante a época das chuvas, em amostras simulando o pastejo, DERESZ (1994) encontrou taxas diárias de acúmulo de matéria seca de capim-elefante de até $100 \mathrm{~kg} / \mathrm{ha}$. Produções de leite de $15.000 \mathrm{~kg} / \mathrm{ha} / 180$ dias, durante a estação chuvosa, foram relatadas por DERESZ e MOZZER (1994), usando vacas mestiças Holandês x Zebu em pastejo rotativo nessa forrageira. Produções diárias de leite na estação das chuvas, de 12 a $14 \mathrm{~kg} /$ vaca sem concentrado em pastagem de capim-elefante manejado em sistema rotativo com período de descanso de 30 dias e adubado com $200 \mathrm{~kg} / \mathrm{ha} /$ ano de $\mathrm{N}$ e de $\mathrm{K} 2 \mathrm{O}$, foram observadas por DERESZ et al. (1994). Esses níveis de produção de leite a pasto com forrageiras tropicais estão próximos do limite máximo obtido com vacas de bom potencial genético, que corresponde a produções por lactação ao redor de $4.500 \mathrm{~kg}$. COWAN et al. (1993), ALVIM et al. (1996) e VILELA et al. (1996), trabalhando com vacas da raça Holandesa, alcançaram produções bem próximas de 12 a $14 \mathrm{~kg} / \mathrm{vaca} / \mathrm{dia}$, quando se descartou o efeito da suplementação do concentrado.

$O$ efeito da suplementação da pastagem com diferentes níveis de concentrado sobre a produção de leite em pastagens tropicais foi avaliado por VALLE et al. (1987), DERESZ et al. (1994), ALVIM et al. (1996) e VILELA et al. (1996). A resposta da suplementação com concentrado em pastagens tropicais varia de 0,5 a $1,0 \mathrm{~kg}$ de leite para cada $1,0 \mathrm{~kg}$ de concentrado fornecido. VALLE et al. (1987), trabalhando com vacas mestiças $\mathrm{H}$ x Z, e ALVIM et al. (1996) e VILLELA et al. (1996), com vacas da raça Holandesa obtiveram resposta em torno de $1,0 \mathrm{~kg}$. Entretanto, ARONOVICH et al. (1965) encontraram em torno de $0,5 \mathrm{~kg}$ de leite para $1,0 \mathrm{~kg}$ de concentrado.

A disponibilidade de forragem em pastagens de capim-elefante adubado e manejado em sistema de pastejo rotativo é pouco estudado na literatura nacional. SOARES et al. (1999) observaram disponibilidade média de matéria seca de $2299 \mathrm{~kg} / \mathrm{ha}$ durante os meses de janeiro e março e $473 \mathrm{~kg} /$ ha no mês de julho. OLIVO et al. (1992) observaram disponibilidade média de 1842 a $2816 \mathrm{~kg} / \mathrm{ha}$ nos meses de dezembro a janeiro, respectivamente. AROEIRA et al. (1998) encontraram valores médios de $1900 \mathrm{~kg} / \mathrm{ha}$ de maté- ria seca para capim-elefante manejado com 30 dias de descanso e adubado com $200 \mathrm{~kg} / \mathrm{ha} /$ ano de nitrogênio.

O objetivo deste trabalho foi avaliar o efeito da suplementação concentrada da pastagem de capimelefante, manejada em sistema rotativo, sobre a produção e composição de leite e a variação do peso vivo de vacas mestiças Holandês x Zebu, produzindo no início da lactação em torno de 14 a 16 kg/vaca/dia.

\section{Material e Métodos}

O experimento foi conduzido em uma área de pastagem exclusiva de capim-elefante, a qual vem sendo utilizada em pastejo rotativo desde 1988.

O solo da área experimental é do tipo Latossolo Vermelho-Amarelo, distrófico de textura argilosa e relevo variando de encosta à baixada. A análise química feita na estação seca de 1993 mostrou as seguintes características: $\mathrm{pH}$ em água $=4,70$; $\mathrm{P}=9,15 \mathrm{mg} / \mathrm{dm}^{3} ; \mathrm{K}=128 \mathrm{mg} / \mathrm{dm}^{3} ; \mathrm{Al}=0,16 \mathrm{cmolc} / \mathrm{dm}^{3}$; $\mathrm{Ca}=1,95 \mathrm{cmolc} / \mathrm{dm}^{3} ; \mathrm{Mg}=0,50 \mathrm{cmolc} / \mathrm{dm}^{3} ;$ $\mathrm{CTC}=9,42 \mathrm{cmolc} / \mathrm{dm} 3$ e $\mathrm{MO}=3,40 \mathrm{~g} / \mathrm{kg}$.

Os dois tratamentos estudados foram: pastejo em capim-elefante sem fornecimento de concentrado para os animais (SC) e pastejo com fornecimento de $2 \mathrm{~kg}$ de concentrado/vaca/dia (CC), durante todo o período experimental. A coleta de dados começou em 24/11/93 e terminou em 08/06/94.

O concentrado oferecido era composto de $65 \%$ de milho grão, $20 \%$ de farelo de trigo, $10 \%$ de farelo de algodão, $2 \%$ de uréia, $2 \%$ de calcário e $1 \%$ de mistura mineral. A composição química média na base da matéria seca foi de $20 \%$ de proteína bruta, $75 \%$ de nutrientes digestíveis totais e $32 \%$ de fibra em detergente neutro.

Foram usadas doze vacas mestiças Holandês $\mathrm{x}$ Zebu, de diferentes graus de sangue, sendo seis/tratamento, com cerca de 30 a 40 dias pós-parto e peso vivo médio de $488 \mathrm{~kg}$. O delineamento experimental foi em blocos ao acaso e os blocos foram formados com base na produção de leite e no peso vivo das vacas, no início da lactação.

A pastagem foi manejada em sistema de pastejo rotativo com três dias de ocupação dos piquetes e 30 dias de descanso. A área foi dividida em 44 piquetes de $606 \mathrm{~m}^{2}, 22$ para cada tratamento, representando duas repetições de área, constituída cada uma de 11 piquetes. A taxa de lotação da pastagem foi de 4,5 vacas/ha.

A pastagem foi adubada anualmente durante a estação das chuvas com $200 \mathrm{~kg} / \mathrm{ha}$ de nitrogênio e de $\mathrm{K}^{2} \mathrm{O}$, fracionados em três aplicações iguais (novembro, 
Rev. bras. zootec.

janeiro e março). Durante o experimento, a primeira aplicação de nitrogênio (uréia) e potássio (cloreto de potássio) foi feita no início de novembro de 1993 e distribuída na área toda. A segunda aplicação iniciou em 13/12/93 e foi feita gradualmente sempre após a saída das vacas dos piquetes. A terceira aplicação iniciou-se em 13/02/94 e terminou no início de abril, também realizada sempre após a saída das vacas dos piquetes.

As aplicações de fósforo (superfosfato simples) e calcário dolomítico também foram feitas a lanço de uma só vez, no início da estação das chuvas, na base de $40 \mathrm{~kg} / \mathrm{ha} / \mathrm{ano}$ de $\mathrm{P}_{2} \mathrm{O}_{5}$ e $1000 \mathrm{~kg} / \mathrm{ha} / \mathrm{ano}$, respectivamente.

À medida que as vacas iam parindo, entravam nos piquetes até completarem as seis vacas/tratamento. Os piquetes foram manejados para obter-se altura de resíduo pós-pastejo em torno de $90-100 \mathrm{~cm}$. O estabelecimento da altura do resíduo foi feito por meio de roçada manual, antes do início do trabalho e sempre que necessário durante o período experimental, logo após a saída das vacas do piquete.

A estimativa da disponibilidade e qualidade de forragem foi feita mensalmente, um dia antes da entrada dos animais, por meio da técnica do pastejo simulado, observando-se a altura do resíduo dos piquetes recém-desocupados. $\mathrm{O}$ pastejo simulado foi feito em touceiras representativas, com disponibilidade de forragem alta e baixa, em dois pontos diferentes e em cada repetição de área dos piquetes de cada tratamento. As folhas e os caules provenientes da rebrota foram retirados para a estimativa da produção de forragem. A disponibilidade de forragem por hectare foi estimada por intermédio da produção média das duas touceiras e do número de touceiras contidas em uma área de $100 \mathrm{~m}^{2}$ de cada piquete. Para obter estes valores, usou-se a disponibilidade de matéria seca por hectare, dividida pelos 11 piquetes; o resultado foi dividido pela taxa de lotação (4,5 vacas/ha) e novamente dividido por três, que foi o período de ocupação dos piquetes. As amostras para análise química da forragem foram coletadas durante os três dias de ocupação do piquete, por intermédio do método de extrusa, utilizando-se dois animais, extras por tratamento, canulados no esôfago e equipados com bolsas para a coleta das amostras de forragem, nos diferentes tratamentos, nos meses de janeiro, março, abril e maio de 1994.

As vacas foram ordenhadas manualmente, sem a presença do bezerro duas vezes ao dia, sendo a primeira ordenha das 6 às 8 h30 e a segunda das 14 às 16h. Durante o intervalo das ordenhas, as vacas permaneceram em currais separados por tratamento, onde tinham acesso à sombra, água e mistura mineral à vontade. Não havia bebedouros, nem cochos de sal mineral nos piquetes.

As vacas foram pesadas semanalmente, sempre logo após a ordenha da manhã. A amostragem do leite para a determinação de gordura, proteína e extrato seco total foi feita semanalmente em quantidades proporcionais à produção de leite da ordenha da tarde e da manhã, em frascos de plástico de $200 \mathrm{~mL}$ providos de dicromato de potássio.

\section{Resultados e Discussão}

Os dados médios de precipitação e o número médio de dias de ocorrência de chuva, no período de 1980 a 1992, obtidos no posto meteorológico localizado a aproximadamente $1 \mathrm{~km}$ de distância do local do experimento, são mostrados na Tabela 1. Observa-se

Tabela 1 - Dados médios de precipitação $(\mathrm{mm})$ e número médio de dias de ocorrência de chuvas durante o período de 1980/92

Table 1 - Average data of monthly rainfall $(\mathrm{mm})$ and number of days raining in each month, from 1980 to 1992

\begin{tabular}{|c|c|c|}
\hline \multirow[b]{2}{*}{$\begin{array}{l}\text { Mês } \\
\text { Month }\end{array}$} & \multicolumn{2}{|c|}{$\begin{array}{c}\text { Período 1980/1992 } \\
\text { Period 1980/1992 }\end{array}$} \\
\hline & $\begin{array}{c}\text { Precipitação }(\mathrm{mm}) \\
\text { Rainfall }\end{array}$ & $\begin{array}{c}\mathrm{N}^{\circ} \text { dias } \\
\text { Days raining }\end{array}$ \\
\hline $\begin{array}{l}\text { Jan. } \\
\text { Jan. }\end{array}$ & 381 & 19 \\
\hline $\begin{array}{l}\text { Fev. } \\
\text { Feb. }\end{array}$ & 194 & 12 \\
\hline $\begin{array}{l}\text { Mar. } \\
\text { Mar. }\end{array}$ & 220 & 14 \\
\hline $\begin{array}{l}\text { Abr. } \\
\text { Apr. }\end{array}$ & 92 & 8 \\
\hline $\begin{array}{l}\text { Maio } \\
\text { May }\end{array}$ & 46 & 5 \\
\hline $\begin{array}{l}\text { Jun. } \\
\text { Jun. }\end{array}$ & 32 & 4 \\
\hline $\begin{array}{l}\text { Jul. } \\
\text { Jul. }\end{array}$ & 16 & 3 \\
\hline $\begin{array}{l}\text { Ago. } \\
\text { Aug. }\end{array}$ & 20 & 4 \\
\hline $\begin{array}{l}\text { Set. } \\
\text { Sep. }\end{array}$ & 91 & 8 \\
\hline $\begin{array}{l}\text { Out. } \\
\text { Oct. }\end{array}$ & 110 & 11 \\
\hline $\begin{array}{l}\text { Nov. } \\
\text { Nov. }\end{array}$ & 200 & 14 \\
\hline $\begin{array}{l}\text { Dez. } \\
\text { Dec. }\end{array}$ & 291 & 19 \\
\hline
\end{tabular}


que a estação chuvosa usualmente se concentra de setembro a abril; contudo, os dados de precipitação dos meses de abril e setembro são inferiores a $100 \mathrm{~mm}$. Nota-se também que a distribuição de chuva neste período é boa, visto que o número médio de dias de ocorrência de chuva mensal é superior a 11.

$\mathrm{Na}$ Tabela 2, são apresentados os dados médios de composição química e de digestibilidade in vitro da matéria seca (DIVMS) de amostras de extrusas dos animais em pastagem de capim-elefante. O coeficiente de variação para os dados de matéria seca foi de $3,3 \%$, o qual pode ser considerado baixo. Observa-se que os teores de MS foram relativamente baixos nos dois tratamentos. Os menores valores foram observados nos meses de janeiro e maio. Entretanto, não houve diferença $(\mathrm{P}>0,05)$ entre os tratamentos, no teor de matéria seca, em nenhum dos meses estudados, o que pode estar relacionado com a contaminação das amostras com a saliva. A coleta de amostras por meio de extrusa provoca alta contaminação com saliva, resultando em baixos teores de matéria seca. DERESZ (1994) observou valores de $17,5 \%$ de matéria seca em amostras de capimelefante simulando o pastejo e manejado com 30 dias de descanso.
Não houve diferença $(\mathrm{P}>0,05)$ entre tratamentos no teor de proteína bruta nos meses estudados. O coeficiente de variação para os dados de proteína bruta foi de $12 \%$, o qual pode ser considerado baixo. O teor de PB está abaixo dos valores esperados para o capim-elefante adubado com nitrogênio e manejado com 30 dias de descanso.

Não houve diferença $(P>0,05)$ entre tratamentos no teor de fibra em detergente neutro (FDN). O coeficiente de variação para os dados de FDN foi de $2,5 \%$, o qual pode ser considerado bastante baixo. $\mathrm{O}$ teor de FDN nas amostras esteve ao redor de $70 \%$.

Não houve diferença $(P>0,05)$ entre tratamentos na DIVMS nos meses estudados. O coeficiente de variação para os dados de digestibilidade foi de $4,2 \%$, o qual pode ser considerado baixo. A maioria dos valores observados está na faixa de 60 a $66 \%$, com exceção do mês de maio, em que os valores estão na faixa de $50 \%$ nos dois tratamentos.

DERESZ (1994) observou valores de 15,5\% de proteína bruta, valores de FDN próximos aos obtidos neste trabalho e de $68,5 \%$ de digestibilidade in vitro da matéria seca, em amostras de capim-elefante simulando o pastejo, manejado com 30 dias de descanso.

Os resultados de composição química e da

Tabela 2 - Teores médios de matéria seca (MS), proteína bruta (PB), fibra em detergente neutro (FDN) e digestibilidade in vitro da matéria seca (DIVMS) do capim-elefante, em amostras de extrusa, no ano de 1994

Table 2 - Average data of dry matter (DM), crude protein (CP), neutral detergent fiber (NDF) and in vitro dry matter digestibility (IVDMD) of esophageal samples of elephantgrass collected in 1994

\begin{tabular}{|c|c|c|c|c|}
\hline \multirow{3}{*}{$\begin{array}{l}\text { Variável } \\
\text { Variable }\end{array}$} & \multicolumn{4}{|c|}{$\begin{array}{l}\text { Mês } \\
\text { Month }\end{array}$} \\
\hline & Janeiro & Março & Abril & Maio \\
\hline & January & March & April & May \\
\hline $\begin{array}{l}\mathrm{MS}(\%) \\
D M\end{array}$ & $11,7 \pm 0,3^{\mathrm{a}}$ & $12,9 \pm 0,2^{\mathrm{a}}$ & $12,7 \pm 0,3^{\mathrm{a}}$ & $11,3 \pm 0,4^{\mathrm{a}}$ \\
\hline $\begin{array}{l}\mathrm{PB}(\%) \\
C P\end{array}$ & $13,0 \pm 0,3^{\mathrm{a}}$ & $14,5 \pm 0,9^{\mathrm{a}}$ & $9,8 \pm 1,6^{\mathrm{a}}$ & $13,4 \pm 0,5^{\mathrm{a}}$ \\
\hline $\begin{array}{l}\mathrm{FDN}(\%) \\
N D F\end{array}$ & $71,2 \pm 0,7^{\mathrm{a}}$ & $71,0 \pm 0,4^{\mathrm{a}}$ & $72,1 \pm 0,4^{\mathrm{a}}$ & $71,0 \pm 0,5^{\mathrm{a}}$ \\
\hline DIVMS (\%) & $65,9 \pm 1,2^{\mathrm{a}}$ & $63,0 \pm 1,3^{\mathrm{a}}$ & $60,8 \pm 0,1^{\mathrm{a}}$ & $50,0 \pm 4,5^{\mathrm{a}}$ \\
\hline & \multicolumn{4}{|c|}{$\begin{array}{c}\text { Tratamento }(\mathrm{CC}) \\
\text { Treatment }(C C)\end{array}$} \\
\hline $\begin{array}{l}\mathrm{MS}(\%) \\
D M\end{array}$ & $12,3 \pm 0,3^{\mathrm{a}}$ & $12,8 \pm 0,4^{\mathrm{a}}$ & $13,1 \pm 0,1^{\mathrm{a}}$ & $11,0 \pm 0,5^{\mathrm{a}}$ \\
\hline $\begin{array}{l}\mathrm{PB}(\%) \\
C P\end{array}$ & $12,1 \pm 0,2^{\mathrm{a}}$ & $14,6 \pm 0,2^{\mathrm{a}}$ & $10,1 \pm 0,8^{\mathrm{a}}$ & $14,2 \pm 1,2^{\mathrm{a}}$ \\
\hline $\begin{array}{l}\mathrm{FDN}(\%) \\
N D F\end{array}$ & $69,8 \pm 0,2^{\mathrm{a}}$ & $71,5 \pm 1,7^{\mathrm{a}}$ & $72,5 \pm 0,0^{\mathrm{a}}$ & $69,5 \pm 2,8^{\mathrm{a}}$ \\
\hline $\begin{array}{l}\text { DIVMS }(\%) \\
\text { IVDMD }\end{array}$ & $65,3 \pm 0,9^{a}$ & $64,6 \pm 2,5^{\mathrm{a}}$ & $66,5 \pm 0,5^{\mathrm{a}}$ & $52,3 \pm 0,6^{\mathrm{a}}$ \\
\hline
\end{tabular}

* Médias seguidas de letras iguais na linha para a mesma variável não diferem $(P>0,05)$.

* Means, within a row, followed by the same letter are not different $(P>.05)$. 
DIVMS das extrusas de capim-elefante mostram que esse sistema de coleta parece não ser o mais indicado. REEVES et al. (1996) também observaram que as amostras de forragem coletadas à mão, simulando o pastejo, foram mais representativas para qualidade da forragem do que as amostras coletadas por intermédio da fístula esofageana, nas condições da Austrália. As razões para estas diferenças na composição e digestibilidade deveriam ser melhor estudadas.

Os dados sobre disponibilidade de matéria seca de capim-elefante por hectare são apresentados na Tabela 3. O coeficiente de variação foi de $20,2 \%$, o qual é bastante alto, indicando necessidade de coletar maior número de amostras para obter valor mais representativo. Não houve diferença $(\mathrm{P}>0,05)$ entre tratamentos na disponibilidade de matéria seca por hectare. Observa-se que a disponibilidade de matéria seca por hectare tende a diminuir, à medida que os dias ficam mais curtos. Os menores valores foram observados nos meses de maio e junho, quando, além dos dias curtos, normalmente, começa a faltar chuva e inicia-se a estação seca do ano. Por esta razão, nas condições climáticas da Zona da Mata de Minas Gerais, normalmente, a partir do mês de maio, há necessidade de suplementação volumosa da pasta-

Tabela 3 - Estimativa da disponibilidade média de matéria seca $(\mathrm{kg} / \mathrm{ha})$ em pastagem de capim-elefante com e sem suplementação durante a estação das chuvas de 1993/94

Table 3 - $\quad$ Average dry matter availability $(\mathrm{kg} / \mathrm{ha}$ ) of elephantgras during the rainy season from 1993 to 1994

\begin{tabular}{|c|c|c|}
\hline \multirow[b]{2}{*}{$\begin{array}{l}\text { Mês } \\
\text { Month }\end{array}$} & \multicolumn{2}{|c|}{$\begin{array}{c}\text { Tratamento } \\
\text { Treatment }\end{array}$} \\
\hline & $\mathrm{SC}$ & $\mathrm{CC}$ \\
\hline $\begin{array}{l}\text { Nov. } \\
\text { Nov. }\end{array}$ & $1850 \pm 282^{\mathrm{a}}$ & $1717 \pm 199^{a}$ \\
\hline & $1555 \pm 144^{\mathrm{a}}$ & $1555 \pm 97$ \\
\hline $\begin{array}{l}\text { Jan. } \\
\text { Jan. }\end{array}$ & $1881 \pm 175^{\mathrm{a}}$ & $1687 \pm 632$ \\
\hline $\begin{array}{l}\text { Mar. } \\
\text { Mar. }\end{array}$ & $2369 \pm 127^{\mathrm{a}}$ & $2241 \pm 263^{a}$ \\
\hline $\begin{array}{l}\text { Abr. } \\
\text { Apr. }\end{array}$ & $1835 \pm 156^{\mathrm{a}}$ & $1617 \pm 262$ \\
\hline $\begin{array}{l}\text { Maio } \\
\text { May. }\end{array}$ & $1249 \pm 185^{\mathrm{a}}$ & $1342 \pm 100^{\mathrm{a}}$ \\
\hline $\begin{array}{l}\text { Jun. } \\
\text { Jun. }\end{array}$ & $721 \pm 118^{\mathrm{a}}$ & $587 \pm 78^{\mathrm{a}}$ \\
\hline Total & 11.460 & 10.746 \\
\hline
\end{tabular}

* Médias seguidas de letras iguais na linha não diferem $(P>0,05)$.

* Means, within a row, followed by the same letter are not significant $(P>05)$. gem. Em ambos os tratamentos, o maior valor de disponibilidade de matéria seca por hectare encontrado foi no mês de março e o menor valor no mês de junho. SOARES et al. (1999) encontraram valores de disponibilidade de matéria seca de capim-elefante bastante semelhantes a estes nos diferentes meses do ano.

Na Tabela 4, é apresentada a disponibilidade média de matéria seca por vaca por dia. Não houve diferença $(\mathrm{P}>0,05)$ entre os tratamentos na disponibilidade média mensal de matéria seca por vaca por dia nos diferentes meses do ano. O maior valor encontrado foi no mês de março para os dois tratamentos e o menor valor, no mês de junho, com apenas 4,9 e 4,0 kg de matéria seca/vaca/dia nos tratamentos SC e CC, respectivamente. Resultados semelhantes foram observados por (AROEIRA et al., 1996 e SOARES et al., 1999) em pastagem de capim-elefante.

$\mathrm{Na}$ Tabela 5 são apresentadas as produções médias de leite, sem corrigir para $4 \%$ de gordura. Observa-se que a produção diária média de leite no tratamento SC foi de $11,9 \mathrm{~kg} / \mathrm{vaca}$ e aquela no tratamento CC, de 13,4 kg/vaca. A diferença média de leite entre os tratamentos foi variável entre os períodos; nos primeiros 30 dias, foi de $0,9 \mathrm{~kg}$ e no

Tabela 4 - Estimativa de disponibilidade média de matéria seca (kg/vaca/dia) em pastagem de capimelefante, com e sem suplementação durante a estação das chuvas de 1993/94

Table 4 - Average dry matter availability ( $\mathrm{kg} / \mathrm{cow} / \mathrm{day})$ of elephantgrass pasture supplemented or not during the rainy season from 1993 to 1994

\begin{tabular}{|c|c|c|}
\hline \multirow[b]{2}{*}{$\begin{array}{l}\text { Mês } \\
\text { Month }\end{array}$} & \multicolumn{2}{|c|}{$\begin{array}{c}\text { Tratamento } \\
\text { Treatment }\end{array}$} \\
\hline & $\mathrm{SC}$ & $\mathrm{CC}$ \\
\hline $\begin{array}{l}\text { Nov. } \\
\text { Nov. }\end{array}$ & $12,5 \pm 1,9^{\mathrm{a}}$ & $11,6 \pm 1,3^{\mathrm{a}}$ \\
\hline $\begin{array}{l}\text { Dez. } \\
\text { Dec. }\end{array}$ & $10,5 \pm 1,0^{\mathrm{a}}$ & $10,5 \pm 0,7^{\mathrm{a}}$ \\
\hline $\begin{array}{l}\text { Jan. } \\
\text { Jan. }\end{array}$ & $12,7 \pm 1,2^{\mathrm{a}}$ & $11,4 \pm 0,4^{\mathrm{a}}$ \\
\hline $\begin{array}{l}\text { Mar. } \\
\text { Mar. }\end{array}$ & $16,0 \pm 0,9^{a}$ & $15,1 \pm 1,8^{\mathrm{a}}$ \\
\hline $\begin{array}{l}\text { Abr. } \\
\text { Apr. }\end{array}$ & $12,4 \pm 1,0^{\mathrm{a}}$ & $10,9 \pm 0,2^{a}$ \\
\hline $\begin{array}{l}\text { Maio } \\
\text { May. }\end{array}$ & $8,4 \pm 1,3^{\mathrm{a}}$ & $9,0 \pm 0,7^{\mathrm{a}}$ \\
\hline $\begin{array}{l}\text { Jun. } \\
\text { Jun. } \\
\end{array}$ & $4,9 \pm 0,8^{\mathrm{a}}$ & $4,0 \pm 0,5^{\mathrm{a}}$ \\
\hline
\end{tabular}

* Médias seguidas de letras iguais na linha não diferem $(P>0,05)$.

* Means, within a row, followed by the same letter are not significant ( $P>.05)$. 
202

Tabela 5 - Produção média de leite não corrigido para 4\% gordura (kg/vaca.dia) de vacas mestiças $\mathrm{H} \times \mathrm{Z}$, em pastagem de capim-elefante com e sem concentrado durante a estação das chuvas de 1993/94

Table 5 - Average milk yield ( $\mathrm{kg} / \mathrm{cow}$. day) not $4 \%$ fat corrected of crossbred $H \times Z$ cows on elephantgrass pasture supplemented or not during the rainy season of 1993/94

\begin{tabular}{lccc}
\hline & \multicolumn{2}{c}{$\begin{array}{c}\text { Tratamento } \\
\text { Treatment }\end{array}$} & $\begin{array}{c}\text { Erro-padrão } \\
\text { da média } \\
\text { Período(dias) } \\
\text { Period (days) }\end{array}$ \\
\cline { 2 - 3 } & $\mathrm{SC}$ & $\mathrm{CC}$ & $\begin{array}{c}\text { Standard error } \\
\text { of mean }\end{array}$ \\
\hline $1-30$ & 14,1 & 15,0 & \\
$31-60$ & 13,3 & 14,9 & \\
$61-90$ & 11,4 & 13,2 & \\
$91-120$ & 11,7 & 13,3 & \\
$121-150$ & 11,5 & 12,5 & \\
$151-180$ & 9,3 & 11,6 & \\
Média & $11,9^{\mathrm{a}}$ & $13,4^{\mathrm{b}}$ & 0,5 \\
Mean & & & \\
\hline
\end{tabular}

período de 151 a 180 dias, de $2,3 \mathrm{~kg}$.

A diferença média durante o período experimental foi de $1,5 \mathrm{~kg}$ de leite entre o tratamento com 2,0 kg de concentrado por vaca/dia e sem concentrado, respectivamente. Isto representa resposta de $0,75 \mathrm{~kg}$ de leite para cada $1,0 \mathrm{~kg}$ de concentrado fornecido. VILLELA et al. (1996) observaram resposta de 1,0 kg de leite para cada $1 \mathrm{~kg}$ de concentrado para vacas da raça Holandesa em pastagem de coast-cross, ao passo que DERESZ et al. (1994) observaram resposta média de $0,6 \mathrm{~kg}$ de leite para cada $1 \mathrm{~kg}$ de concentrado para vacas mestiças Holandês x Zebu em pastagem de capim-elefante. Então, se o preço de $1 \mathrm{~kg}$ de leite é igual ao preço de $1,0 \mathrm{~kg}$ de concentrado, não há vantagem econômica de se usar concentrado para aumentar a produção de leite.

Na Tabela 6 e Figura 1 são apresentados os dados de produção média de leite corrigido para $4 \%$ de gordura, não-corrigido e a composição média de gordura, proteína e extrato seco total. Houve diferença $(\mathrm{P}<0,05)$ na produção média de leite corrigido para $4 \%$ de gordura e não-corrigido. Observou-se diferença média de $1,2 \mathrm{~kg}$ de leite corrigido para $4 \%$ de gordura em favor do tratamento recebendo $2,0 \mathrm{~kg}$ de concentrado por vaca/dia. Esta diferença representa resposta média de $0,6 \mathrm{~kg}$ de leite para cada $1,0 \mathrm{~kg}$ de concentrado fornecido, o que é menor que a resposta observada por VILLELA et al. (1996), trabalhando com vacas da raça Holandesa em pastagem de coast-cross, que observaram resposta média em

\section{ERESZ}

torno de $1,0 \mathrm{~kg}$ de leite para cada $1,0 \mathrm{~kg}$ de concentrado fornecido.

Os resultados obtidos mostram que é possível produzir, em média, durante um período de 198 dias, até 11,9 e $11,4 \mathrm{~kg} / \mathrm{vaca} / \mathrm{dia}$ de leite não-corrigido e corrigido para $4 \%$ de gordura, em pastagem de capim-elefante adubada e manejada em sistema de pastejo rotativo, com 30 dias de descanso e três dias de ocupação do piquete, com taxa de lotação de 4,5 vacas/ha, durante a época das chuvas, sem suplementação com concentrado. Esse nível de produção de leite, combinado com a taxa de lotação (4,5 vacas/ha), resulta em valor bem próximo do potencial de produção de leite de forrageiras tropicais, quando são bem manejadas, e utilizando vacas mestiças Holandês x Zebu com potencial de produção de leite por lactação de 4000 a $4500 \mathrm{~kg}$. Resultados semelhantes foram publicados por COWAN et al. (1993) com vacas Holandesas nas condições da Austrália.

Não houve diferença $(\mathrm{P}>0,05)$ na composição química do leite entre tratamentos para o teor de gordura e extrato seco total, entretanto, houve diferença $(\mathrm{P}<0,05)$ para o teor de proteína do leite. As vacas do tratamento $C C$ produziram leite com mais proteína que aquelas do tratamento SC. BACHMAN (1992) discute o mecanismo de ação envolvido no

Tabela 6 - Produção (kg/vaca/dia) e composição média de leite de vacas mestiças $\mathrm{H} \times \mathrm{Z}$, em pastagem de capim-elefante, com e sem concentrado, durante a estação chuvosa de 1993/94

Table 6 - Average milk yield (kg/cow/day) and milk composition of crossbred cows (Holstein $x$ Zebu) grazing elephantgrass pasture supplemented or not during the rainy season of 1993/94

\begin{tabular}{lccc}
\multicolumn{3}{c}{ rainy season of 1993/94 } \\
\hline & \multicolumn{2}{c}{$\begin{array}{c}\text { Tratamento } \\
\text { Treatment }\end{array}$} & $\begin{array}{c}\text { Erro-padrão } \\
\text { da média }\end{array}$ \\
\cline { 2 - 3 } $\begin{array}{l}\text { Período (dias) } \\
\text { Period (days) }\end{array}$ & $\mathrm{SC}$ & $\mathrm{CC}$ & $\begin{array}{c}\text { Standard error } \\
\text { of mean }\end{array}$ \\
\hline $\begin{array}{l}\text { Leite } \\
\text { Milk }\end{array}$ & $11,9^{\mathrm{a}}$ & $13,4^{\mathrm{b}}$ & 0,18 \\
$\begin{array}{l}\text { Leite a 4\% } \\
\text { Milk (4\% fat) }\end{array}$ & $11,4^{\mathrm{a}}$ & $12,6^{\mathrm{b}}$ & 0,23 \\
$\begin{array}{l}\text { Gordura (\%) } \\
\text { Fat (\%) }\end{array}$ & $3,8^{\mathrm{a}}$ & $3,7^{\mathrm{a}}$ & 0,11 \\
$\begin{array}{l}\text { Proteína (\%) } \\
\text { Protein (\%) }\end{array}$ & $3,0^{\mathrm{a}}$ & $3,2^{\mathrm{b}}$ & 0,03 \\
$\begin{array}{l}\text { Extrato seco } \\
\text { total (\%) } \\
\text { Total solids (\%) }\end{array}$ & $12,4^{\mathrm{a}}$ & $12,4^{\mathrm{a}}$ & 0,12 \\
$\begin{array}{l}{ }^{*} \text { Médias seguidas de letras iguais na linha não diferem }(\mathrm{P}>0,05) . \\
\text { * Means, within a row, followed by the same letter are not significant }(P>05) .\end{array}$
\end{tabular}




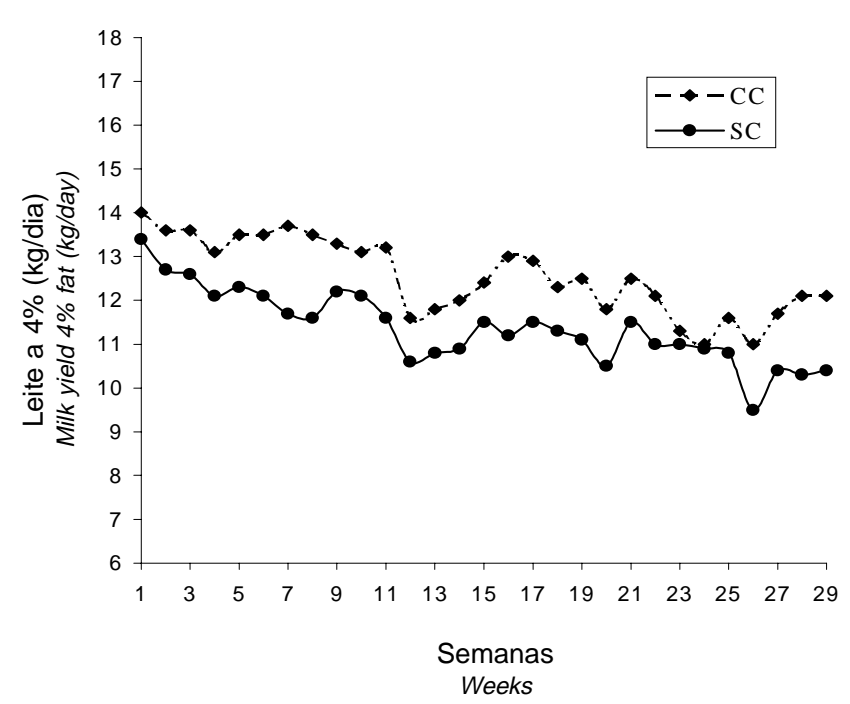

Figura 1 - Produção média de leite de vacas em pastagem de capim-elefante, com e sem concentrado, durante a estação das chuvas de 1993/94.

Figure1 - Average milkyield of cows grazing elephantgrass pasture supplemented or not during the rainy season from 1993 to 1994.

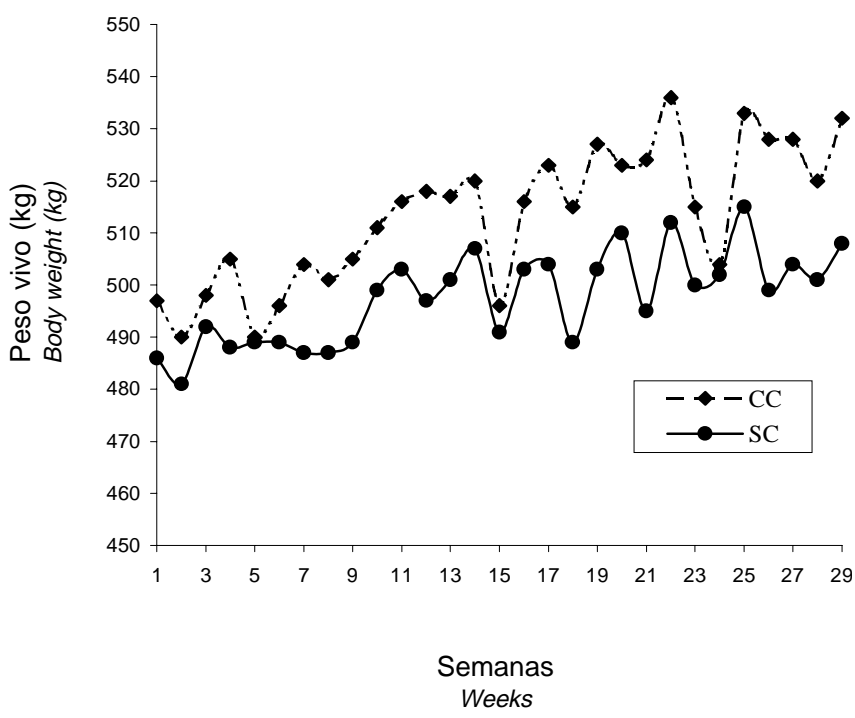

Figura 2 - Variação de peso vivo das vacas em pastagem de capim-elefante, com e sem concentrado, durante a estação das chuvas de 1993/94.

Figure 2 - Body weight changes of cows grazing elephantgrass pasture supplemented or not during the rainy season from 1993 to 1994.

mestiças Holandês x Zebu manejadas em pastagens durante os primeiros 200 dias de lactação.

Na Tabela 7 e Figura 2, são apresentados os dados médios de peso e ganho médio de peso vivo das vacas durante o período experimental. Não houve diferença $(P>0,05)$ entre tratamentos no ganho de peso médio diário nos três períodos avaliados. Observa-se que as vacas dos dois tratamentos ganharam peso nos três períodos avaliados, o que indica que as produções médias de leite foram provenientes da forragem ingerida, e não da mobilização de reservas corporais. É bom salientar que, quando se considera todo o período experimental, a variação média de peso vivo foi muito pequena, ou seja, em torno de $114 \mathrm{e} 180 \mathrm{~g}$ de ganho por dia para os tratamentos SC e CC, respectivamente. Estes resultados concordam com aqueles observados por DERESZ et al. (1994), trabalhando com vacas mestiças em pastagem de capim-elefante.

O coeficiente de variação para a variável ganho de peso foi muito alto para os três períodos analisados. O coeficiente de variação foi de 99,2; 93,9 e 62,6\% para os períodos 1-10 semanas, 10-29 semanas e 1-29 semanas, respectivamente. Com coeficiente de variação tão elevado, fica muito difícil detectar diferença estatística significativa, o que pode ter sido a principal causa de não observação de diferença significativa entre os tratamentos. 


\section{Conclusões}

Os valores de disponibilidade de matéria seca por hectare e a qualidade da pastagem selecionada, durante a época das chuvas, foram suficientes para atender as exigências de mantença e produção de leite de vacas mestiças Holandês x Zebu com potencial de produção de leite no início da lactação de $15 \mathrm{~kg}$ por dia.

Vacas mestiças Holandês x Zebu, com potencial de produção de leite de até $15 \mathrm{~kg}$ por dia, no início da lactação, podem ser manejadas em pastagem de capim-elefante com taxa de lotação de 4,5 vacas/ha, sem suplementação durante a época das chuvas.

A suplementação da pastagem de capim-elefante, durante a época das chuvas, não foi vantajosa, por causa do pequeno aumento na produção de leite observado.

A produção de leite observada não foi proveniente da mobilização de reservas corporais, uma vez que as vacas ganharam peso durante o período experimental.

\section{Referências Bibliográficas}

ALVIM, M.J., VILELA, D., CÓSER, A.C. et al. Efeitos de dois níveis de concentrado sobre a produção de leite de vacas da raça holandesa em pastagem de coast-cross. In: REUNIÃO ANUAL DA SOCIEDADE BRASILEIRA DE ZOOTECNIA, 33, 1996. Fortaleza, CE. Anais... Fortaleza: SBZ. 1996. p.172-173.

ARONOVICH, S., CORRÊA, A.N.S., FARIA, E.V. O uso de concentrados na alimentação de vacas leiteiras em boas pastagens de capim-pangola. I - Resultados de verão. In: CONGRESSO INTERNACIONAL DE PASTAGENS, 9, 1965, Anais... São Paulo, 1965. v.2, p.919-921.

AROEIRA, L.J.M., LOPES, F.C., MALDONADO-VASQUES, H. et al. Disponibilidade e consumo do capim-elefante (Pennisetum purpureum, Schum.) sob pastejo de vacas em lactação. In: REUNIÃO ANUAL DA SOCIEDADE BRASILEIRA DE ZOOTECNIA, 33, 1996, Fortaleza. Anais... Fortaleza: SBZ, 1996. p.177-179.

BACHMAN, K.C. 1992. Managing milk composition. In: VAN HORN H.H., WILCOX, C.J. (Eds.) Large dairy herd management. Champaign: American Dairy Science Association, p.336-346.

BRITTO, D.P.P.S., ARONOVICH, S., RIBEIRO, H. Comparação entre duas variedades de capim-elefante (Pennisetum purpureum, Schum.) e de seis diferentes espaços de tempo entre os cortes da planta. In: CONGRESSOINTERNACIONAL DE PASTAGENS, 1965, São Paulo. Anais... São Paulo: Secretaria da Agricultura, 1965. p.1683-1685.

COWAN, R.T., MOSS, R.J., KERR, D.V. 1993. Northern dairy feedbase 2001. 2. Summer feeding systems. Trop. Grass., 27:150-161.
DERESZ, F. Manejo de pastagem de capim-elefante para produção de leite e carne. In: SIMPÓSIO SOBRE CAPIMELEFANTE, 2, 1994, Juiz de Fora. Anais... Coronel Pacheco, MG: Embrapa, 1994. p.116-137.

DERESZ, F., MOZZER, O.L. Produção de leite em pastagem de capim-elefante. In: CAPIM-ELEFANTE: PRODUÇÃO E UTILIZAÇÃO, Coronel Pacheco, MG: Embrapa, 1994. p.155-216.

DERESZ, F., CÓSER, A.C., MARTINS, C.E. et al. Utilização do capim-elefante (Pennisetum purpureum, Schum.) para a produção de leite. In: SIMPÓSIO BRASILEIRO DE FORRAGEIRAS E PASTAGENS, 1994, Campinas. Anais... Campinas, SP: CBNA, 1994. p.103-199.

FARIA, V. P. Formas de uso do capim-elefante. In: SIMPÓSIO SOBRE CAPIM-ELEFANTE, 2, 1994, Juiz de Fora. Anais... Coronel Pacheco, MG: Embrapa Gado de Leite, 1994. p.139-148.

GRANT, R.J., VAN SOEST, P.J., McDOWELL, R.E. et al. 1974. Intake, digestibility and metabolic loss of napier grass by cattle and buffaloes when fed wilted, chopped and whole. J. Anim. Sci., 39(2):423-434.

HOLMES, C.W. Produção de leite a baixo custo em pastagens: uma análise do sistema neozelandês. In: CONGRESSO BRASILEIRO DE GADO LEITEIRO, 2, 1995, Piracicaba. Anais... Piracicaba: FEALQ, 1996. p.69-95.

OLIVO, C.J., MOREIRA, J.C., BARRETO, I.L. et al. 1992. Utilização de pastagens de capim-elefante e capim-setária como base da alimentação de vacas em lactação, durante o verão. R. Soc. Bras. Zootec., 21(3):347-352.

REEVES, M., FULKERSON, W.F., KELLAWAY, R.C. et al. 1996. A comparison of three techniques to determine the herbage intake of dairy cows grazing kikuyu (Pennisetum clandestinum) pasture. Austr. J. Exp. Agric., 36:23-30.

SOARES, J.P.G., AROEIRA, L.J.M., PEREIRA, O.G., et al. 1999. Capim-elefante (Pennisetum purpureum Schum.) sob duas doses de nitrogênio. Consumo e produção de leite. R. Soc. Bras. Zootec., 28:889-897.

VALLE, L.C.S., MOZZER, O.L., VILLAÇA, H.A. et al. Níveis de concentrado para vacas em lactação em pastagem de capimelefante (Pennisetum purpureum Schum.) no período das águas. In: REUNIÃO ANUAL DA SOCIEDADE BRASILEIRA DEZOOTECNIA, 24., Brasília, DF. Anais... Brasília: SBZ, 1987. 56p.

VILELA, D., ALVIM, M.J., RESENDE, J.C. et al. Produção de leite em pastagem de coast-cross (Cynodon dactylon L. Pers.) suplementada estrategicamente com concentrados. In: REUNIÃO ANUAL DA SOCIEDADE BRASILEIRA DE ZOOTECNIA, 33, 1996, Fortaleza, CE. Anais... Fortaleza: SBZ, 1996. v.3, p.169-171.

Recebido em: 28/12/99

Aceito em: 28/09/00 